\title{
Development of pVCR94 $\Delta$ X from Vibrio cholerae, a prototype for studying multidrug resistant IncA/C conjugative plasmids
}

\author{
Nicolas Carraro, Maxime Sauvé, Dominick Matteau, Guillaume Lauzon, Sébastien Rodrigue and \\ Vincent Burrus *
}

Département de Biologie, Université de Sherbrooke, Sherbrooke, QC, Canada

Edited by:

Daniela Ceccarelli, University of

Maryland, USA

Reviewed by:

Daniele Provenzano, University of

Texas Brownsville, USA

Elisa Taviani, Biotechnology Center

University Eduardo Mondlane,

Mozambique

*Correspondence:

Vincent Burrus, Département de biologie, Université de Sherbrooke 2500 Boulevard de l'Université,

Sherbrooke, QC J1K 2R1, Canada

e-mail:vincent.burrus@

usherbrooke.ca
Antibiotic resistance has grown steadily in Vibrio cholerae over the last few decades to become a major threat in countries affected by cholera. Multi-drug resistance (MDR) spreads among clinical and environmental $V$. cholerae strains by lateral gene transfer often mediated by integrative and conjugative elements (ICEs) of the SXT/R391 family. However, in a few reported but seemingly isolated cases, MDR in V. cholerae was shown to be associated with other self-transmissible genetic elements such as conjugative plasmids. IncA/C conjugative plasmids are often found associated with MDR in isolates of Enterobacteriaceae. To date, IncA/C plasmids have not been commonly found in $V$. cholerae or other species of Vibrio. Here we present a detailed analysis of pVCR94 $\Delta X$ derived from pVCR94, a novel IncA/C conjugative plasmid identified in a $V$. cholerae clinical strain isolated during the 1994 Rwandan cholera outbreak. pVCR94 was found to confer resistance to sulfamethoxazole, trimethoprim, ampicillin, streptomycin, tetracycline, and chloramphenicol and to transfer at very high frequency. Sequence analysis revealed its mosaic nature as well as high similarity of the core genes responsible for transfer and maintenance with other IncA/C plasmids and ICEs of the SXT/R391 family. Although IncA/C plasmids are considered a major threat in antibiotics resistance, their basic biology has received little attention, mostly because of the difficulty to genetically manipulate these MDR conferring elements. Therefore, we developed a convenient derivative from pVCR94, pVCR94 $\Delta \mathrm{X}$, a 120.5-kb conjugative plasmid which only codes for sulfamethoxazole resistance. Using $\mathrm{pVCR} 94 \Delta \mathrm{X}$, we identified the origin of transfer (oriT) and discovered an essential gene for transfer, both located within the shared backbone, allowing for an annotation update of all IncA/C plasmids. pVCR94 $\Delta \mathrm{X}$ may be a useful model that will provide new insights on the basic biology of IncA/C conjugative plasmids.

Keywords: Vibrio cholerae, cholera, antibiotic resistance, IncA/C, conjugative plasmid, pVCR94, oriT, SXT

\section{INTRODUCTION}

Cholera is an infectious disease caused by the Gram-negative bacterium Vibrio cholerae that remains a major threat worldwide, especially for vulnerable territories where water supplies and sanitation are inadequate. The main symptoms of cholera are a profuse watery diarrhea and vomiting caused by the cholera toxin CtxAB encoded by CTX $\phi$, a filamentous phage carried by toxicogenic V. cholerae strains (Waldor and Mekalanos, 1996). The resulting rapid loss of fluids and electrolytes leads to severe and often lethal dehydration of patients within a few hours of onset, making oral antibiotics ineffective. Significant measures have been developed to fight this scourge, from public health improvement to vaccines and antibiotic therapies (Desai and Clemens, 2012; Harris et al., 2012). Since cholera is a self-limiting disease, patients usually recover rapidly with prompt and proper rehydration, and electrolyte replacement. Antimicrobial therapies may considerably reduce the severity of diarrhea and the duration of vibrio excretion yet increase the emergence and development of antibiotic resistance (Harris et al., 2012).
Currently, major mediators of antibiotic resistance in epidemic strains of V. cholerae remain Integrative and Conjugative Elements (ICEs), and mobile and chromosomal integrons (Waldor et al., 1996; Mazel et al., 1998; Hochhut et al., 2001; Burrus et al., 2006a; Mazel, 2006; Pugliese et al., 2009; Wozniak et al., 2009; Stalder et al., 2012). In fact, most epidemic strains recovered in the past 20 years harbor an ICE belonging to the SXT/R391 family (Burrus et al., 2006a; Reimer et al., 2011; Garriss and Burrus, 2013). The characterization of the first multi-drug resistant O139 V. cholerae epidemic strain isolated in India in the early 1990s led to the identification of SXT ${ }^{\mathrm{MO} 10}$, which was responsible for the resistance to sulfamethoxazole and trimethoprim (co-trimoxazole), chloramphenicol, and streptomycin of this isolate (Waldor et al., 1996). Nowadays, SXT-like relatives are found in most recent $V$. cholerae isolates including $\mathrm{O} 1$ strains such as the ones that caused the 2010 cholera epidemic in Haiti (Ceccarelli et al., 2011; Chin et al., 2011; Reimer et al., 2011; Sjolund-Karlsson et al., 2011; Katz et al., 2013). SXT, as well as all related ICEs, spread into and between bacterial populations via conjugation, and ensure 
their vertical inheritance into daughter cells during cell division by integrating into the host chromosome. In addition to resistance to several antibiotics, some members of the SXT/R391 ICEs also encode diguanylate cyclases that may facilitate their dissemination through manipulating the intracellular level of the second messenger c-di-GMP (Bordeleau et al., 2010).

A few $V$. cholerae epidemic surveys report the implication of conjugative plasmids in multi-drug resistance (MDR) (Sundaram and Murthy, 1984; Garrigue et al., 1986; Kruse et al., 1995; Dalsgaard et al., 2000a; Ceccarelli et al., 2006; Pugliese et al., 2009). Recent characterization of MDR in pandemic $V$. cholerae in Eastern China has shown that resistance to co-trimoxazole, ampicillin, streptomycin, gentamicin, tetracycline, and chloramphenicol was conferred by the large conjugative plasmid pMRV150, which belongs to the A/C incompatibility group (IncA/C) (Pan et al., 2008). Strikingly, while O139 epidemic strains isolated before 1997 were devoid of pMRV150, the proportion of isolates harboring pMRV150 or a related plasmid gradually rose to $92 \%$ between 2000 and 2006. IncA/C elements are large $(>100 \mathrm{~kb})$, broad host-range and single-copy conjugative plasmids that are mainly known for their considerable contribution to MDR phenotypes in pathogenic Enterobacteriaceae infecting humans, food products and food-producing animals (Welch et al., 2007; Fernandez-Alarcon et al., 2011). Comparative genomics studies revealed that the majority of the fully or partially sequenced IncA/C plasmids share a highly conserved backbone of genes of nearly $110 \mathrm{~kb}$, coding for the conjugative transfer and replication machinery (Welch et al., 2007; Fricke et al., 2009; Fernandez-Alarcon et al., 2011). Interestingly, every predicted transfer gene encoded by the IncA/C plasmids are found in synteny in SXT/R391 ICEs, and the identities of these predicted protein sequences vary from 34 to $78 \%$ (Wozniak et al., 2009). Despite their prevalence in a wide range of pathogens isolated from very diverse geographic areas and their importance in the spread of MDR, characterization of IncA/C plasmids has been mostly epidemiological and remained limited to typing (Giske et al., 2012), antibiotic resistance profiling (Glenn et al., 2013), sequencing and comparative genomics (Welch et al., 2007; Fricke et al., 2009; Fernandez-Alarcon et al., 2011). Transcriptome analysis of the self-transferrable IncA/C plasmid pAR060302 revealed that most genes remain silent in laboratory conditions with the exception of a toxin/antitoxin gene locus and resistance genes, which seem to be constitutively transcribed (Lang et al., 2012). Interestingly, while little is known regarding their basic biology, IncA/C plasmids have been shown to specifically drive the trans-mobilization of the MDR-conferring Salmonella genomic island 1 (SGI1) of S. enterica (Doublet et al., 2005; Douard et al., 2010).

Rwanda was free of the seventh pandemic of cholera until 1978, when the disease started to be endemic in the African Great Lakes region. In years of political stability, cholera outbreaks in this region were shown to be influenced by climatic conditions, rainfall and fluctuation in plankton populations in what is known as the "cholera paradigm" (Bompangue Nkoko et al., 2011). However, from the 6th of April to the 4th of July 1994, unrest in the population led to a nationwide genocide, and to the exile of an estimated 800000 refugees to the north of Goma, Democratic Republic of the Congo. Lack of an adequate and timely response, size of refugee camps, promiscuity and poor treatment in the early days led to a devastating cholera outbreak in the refugee population, affecting an estimated 36000 individuals. Treatment was limited to oral rehydration in the early days of the outbreak. Isolated strains were shown to belong to the $V$. cholerae O1 El Tor Ogawa serotype, and were resistant to tetracyclines, aminopenicillins, co-trimoxazole, and nifuroxazide (Bioforce, 1996). An increase in resistance to nalidixic acid over the course of the outbreak was also observed, leaving few options for treatment (Cavallo et al., 1995). At the time, lack of data did not allow precise identification of determinants involved in antibiotic resistance.

In this study, we report the characterization of the novel IncA/C plasmid pVCR94, which is responsible for MDR of a Rwandan epidemic $V$. cholerae isolate. Sequence analysis of pVCR94 revealed its mosaic nature as well as the high degree of similarity of the structural genes responsible for transfer and maintenance among other IncA/C plasmids such as pIP1202 from Y. pestis. Transfer assays showed that pVCR94 is capable of mobilizing resistance determinants between $V$. cholerae strains as well as to and from E. coli. Genetic engineering of pVCR94 allowed us to initiate a more mechanistic study of this prototype IncA/C plasmid, in which we experimentally identified the location of the origin of transfer (oriT) together with a novel gene required for conjugative transfer, both within their shared backbone, allowing for an annotation update of all IncA/C plasmids.

\section{MATERIALS AND METHODS \\ BACTERIAL STRAINS AND MEDIA}

The bacterial strains and plasmids used in this study are described in Table 1. The strains were routinely grown in Luria-Bertani (LB) broth at $37^{\circ} \mathrm{C}$ in an orbital shaker/incubator and were preserved at $-80^{\circ} \mathrm{C}$ in $\mathrm{LB}$ broth containing $15 \%$ ( $\mathrm{vol} / \mathrm{vol}$ ) glycerol. For E. coli, antibiotics were used at the following concentrations: ampicillin (Ap), $100 \mu \mathrm{g} / \mathrm{ml}$; chloramphenicol $(\mathrm{Cm})$, $20 \mu \mathrm{g} / \mathrm{ml}$; erythromycin, $200 \mu \mathrm{g} / \mathrm{ml}$; gentamycin (Gn), $10 \mu \mathrm{g} / \mathrm{ml}$; kanamycin $(\mathrm{Kn}), 50 \mu \mathrm{g} / \mathrm{ml}$; rifampicin (Rf), $50 \mu \mathrm{g} / \mathrm{ml}$; spectinomycin (Sp), $50 \mu \mathrm{g} / \mathrm{ml}$; streptomycin, $200 \mu \mathrm{g} / \mathrm{ml}$; sulfamethoxazole $(\mathrm{Su}), 160 \mu \mathrm{g} / \mathrm{ml}$; tetracycline (Tc), $12 \mu \mathrm{g} / \mathrm{ml}$; and trimethoprim (Tm), $32 \mu \mathrm{g} / \mathrm{ml}$. For $V$. cholerae, antibiotics were used at the following concentrations: chloramphenicol, $2 \mu \mathrm{g} / \mathrm{ml}$; kanamycin, $30 \mu \mathrm{g} / \mathrm{ml}$; streptomycin, $10 \mu \mathrm{g} / \mathrm{ml}$; tetracycline, $10 \mu \mathrm{g} / \mathrm{ml}$. When required, bacterial cultures were supplemented with $0.3 \mathrm{mM}$ DL-2, 6-diaminopimelic acid (DAP) or $0.02 \%$ L-arabinose. Antibiotics susceptibility profiling were done in three independent experiments using broth microdilution tests (Jorgensen and Ferraro, 2009).

\section{BACTERIAL CONJUGATION ASSAYS}

Conjugation assays were performed by mixing equal volumes of each donor and recipient strains that were grown overnight at $37^{\circ} \mathrm{C}$. The cells were harvested by centrifugation for $3 \mathrm{~min}$ at $1200 \mathrm{~g}$, washed in 1 volume of LB broth and resuspended in 1/20 volume of $\mathrm{LB}$ broth. Mating mixtures were then deposited on LB agar plates and incubated at $37^{\circ} \mathrm{C}$ for $6 \mathrm{~h}$. The cells were recovered 
Table 1 | List of strains and plasmids used in this study.

\begin{tabular}{|c|c|c|}
\hline Strain or plasmid & Relevant genotype or phenotype & Source or Reference \\
\hline \multicolumn{3}{|l|}{ E. coli } \\
\hline BW25113 & $\mathrm{F}-, \Delta(\operatorname{araD}-\mathrm{araB}) 567, \Delta$ lacZ4787(:::rnB-3), $\lambda^{-}, r p h-1, \Delta(r h a D-r h a B) 568$, hsdR514 & (Datsenko and Wanner, 2000) \\
\hline GG56 & BW25113 Nx $x^{R}$ & G. Garriss \\
\hline CAG18439 & MG1655 lacZU118 lacl42::Tn $10\left(T_{c}^{R}\right)$ & (Singer et al., 1989) \\
\hline VB112 & MG1655 RfR & (Ceccarelli et al., 2008) \\
\hline DPL12 & VB111 $\Delta$ dapA::(erm-pir) $\left(\mathrm{Nx}^{\mathrm{R}} \mathrm{Em}^{\mathrm{R}}\right)$ & D. Poulin-Laprade \\
\hline NC261 & GG56 pVCR94 (Nx $\left.{ }^{R} \mathrm{Su}^{R} \mathrm{Tm}^{\mathrm{R}} \mathrm{Cm}^{\mathrm{R}} \mathrm{Ap}^{\mathrm{R}} \mathrm{Tc}^{\mathrm{R}} \mathrm{Sm}^{\mathrm{R}}\right)$ & This study \\
\hline VB557 & GG56 pVCR94 $\Delta \mathrm{X}\left(\mathrm{Nx}^{\mathrm{R}} \mathrm{Su}^{\mathrm{R}}\right)$ & This study \\
\hline NC207 & VB112 pVCR94 $\left(\mathrm{Rf}^{\mathrm{R}} \mathrm{Su}^{\mathrm{R}} \mathrm{Tm}^{\mathrm{R}} \mathrm{Cm}^{\mathrm{R}} \mathrm{Ap}^{\mathrm{R}} \mathrm{Tc}^{\mathrm{R}} \mathrm{Sm}^{\mathrm{R}}\right)$ & This study \\
\hline MS1 & GG56 [pVCR94 $\left.\Delta \mathrm{X} \Delta \operatorname{oriT}_{1}:: a a d 7\right]\left(\mathrm{Nx}^{\mathrm{R}} \mathrm{Su}^{\mathrm{R}} \mathrm{Sp}^{\mathrm{R}}\right)$ & This study \\
\hline MS2 & GG56 [pVCR94 $\Delta \mathrm{X} \Delta$ vcrx062::aad7] ( $\left.\mathrm{Nx}^{\mathrm{R}} \mathrm{Su}^{\mathrm{R}} \mathrm{Sp}^{\mathrm{R}}\right)$ & This study \\
\hline MS3 & GG56 [pVCR94 $\Delta \mathrm{X} \Delta$ vcrx001::aad7] $\left(\mathrm{Nx}^{\mathrm{R}} \mathrm{Su}^{\mathrm{R}} \mathrm{Sp}^{\mathrm{R}}\right)$ & This study \\
\hline MS4 & VB45 pVCR94 $\Delta X\left(\mathrm{Sp}^{\mathrm{R}} \mathrm{Su}^{\mathrm{R}}\right)$ & This study \\
\hline MS5 & GG56 [pVCR94 $\Delta \mathrm{X} \Delta$ oriT $_{2}:$ :aad7] $\left(\mathrm{Nx}^{\mathrm{R}} \mathrm{Su}^{\mathrm{R}} \mathrm{Sp}^{\mathrm{R}}\right)$ & This study \\
\hline MS6 & GG56 [pVCR94 $\Delta \mathrm{X} \Delta\left(\right.$ oriT $_{2}$-vcrx001)::aad7] $\left(\mathrm{Nx}^{\mathrm{R}} \mathrm{Su}^{\mathrm{R}} \mathrm{Sp}^{\mathrm{R}}\right)$ & This study \\
\hline \multicolumn{3}{|l|}{ V. cholerae } \\
\hline N16961 & O1 El Tor strain $\left(\mathrm{Sm}^{\mathrm{R}}\right)$ & (Heidelberg et al., 2000) \\
\hline E4 & O1 El Tor strain; E7946 derivative $\Delta c t x A B N 4\left(\mathrm{Sm}^{\mathrm{R}} \mathrm{Kn}^{\mathrm{R}}\right)$ & (Goldberg and Mekalanos, 1986) \\
\hline F1939 & $\mathrm{Su}^{\mathrm{R}} \mathrm{Tm}^{\mathrm{R}} \mathrm{O} 1 \mathrm{El}$ Tor 1994 clinical isolate from Rwanda & (O'shea et al., 2004b) \\
\hline pMA1 & pACYC177 'bla::oriT $\left(\mathrm{Kn}^{\mathrm{R}}\right)$ & This study \\
\hline pMA2 & pACYC177 'bla::vcrx062 (Kn $)$ & This study \\
\hline pMA5 & pACYC177 'bla::oriT-vcrx001 $\left(\mathrm{Kn}^{\mathrm{R}}\right)$ & This study \\
\hline
\end{tabular}

$A p^{R}$, ampicillin resistant; $\mathrm{Cm}^{R}$, chloramphenicol resistant; $\mathrm{Em}^{R}$, erythromycin resistant; $\mathrm{Gn}^{R}$, gentamycin resistant; $\mathrm{Kn}^{R}, \mathrm{kanamycin}$ resistant; $\mathrm{Nx}^{R}$, nalidixic acid resistant; $R f^{R}$, rifampicin resistant; $S u^{R}$, sulfamethoxazole resistant; $S m^{R}$, streptomycin resistant; $S p^{R}$, spectinomycin resistant; $T c^{R}$, tetracycline resistant; $T m^{R}$, trimethoprim resistant; Ts, thermosensitive.

from the plates in $1 \mathrm{ml}$ of LB broth and serially diluted before plating. Donors, recipients and exconjugants were selected on LB agar plates containing appropriate antibiotics.

\section{MOLECULAR BIOLOGY METHODS}

Plasmid DNA was prepared using the EZ-10 Spin Column Plasmid DNA Minipreps Kit (Biobasic) according to manufacturer's instructions. All the enzymes used in this study were purchased from New England BioLabs. PCR assays were performed with the primers described in Table 2 . The PCR conditions were as follows: (i) $3 \mathrm{~min}$ at $94^{\circ} \mathrm{C}$; (ii) 30 cycles of $30 \mathrm{~s}$ at $94^{\circ} \mathrm{C}, 30 \mathrm{~s}$ at the appropriate annealing temperature, and $1 \mathrm{~min} / \mathrm{kb}$ at $68^{\circ} \mathrm{C}$; and (iii) $5 \mathrm{~min}$ at $68^{\circ} \mathrm{C}$. When necessary, PCR products were purified using a EZ-10 Spin Column PCR Products Purification Kit (Biobasic) according to manufacturer's instructions. E. coli was transformed by electroporation as described by Dower et al. (1988) in a BioRad GenePulser Xcell apparatus set at $25 \mu \mathrm{F}, 200 \mathrm{~V}$ and $1.8 \mathrm{kV}$ using 1-mm gap electroporation cuvettes. Sequencing reactions were performed by the Plateforme de Séquençage et de Génotypage du Centre de Recherche du CHUL (Québec, QC, Canada).

\section{PLASMIDS CONSTRUCTION}

Plasmids and oligonucleotides used in this study are listed in Tables 1, 2, respectively. $\lambda$ Red recombination encoding plasmid pMS1 was obtained after amplification of the gentamycin 
Table 2 | DNA sequences of oligonucleotides used in this study.

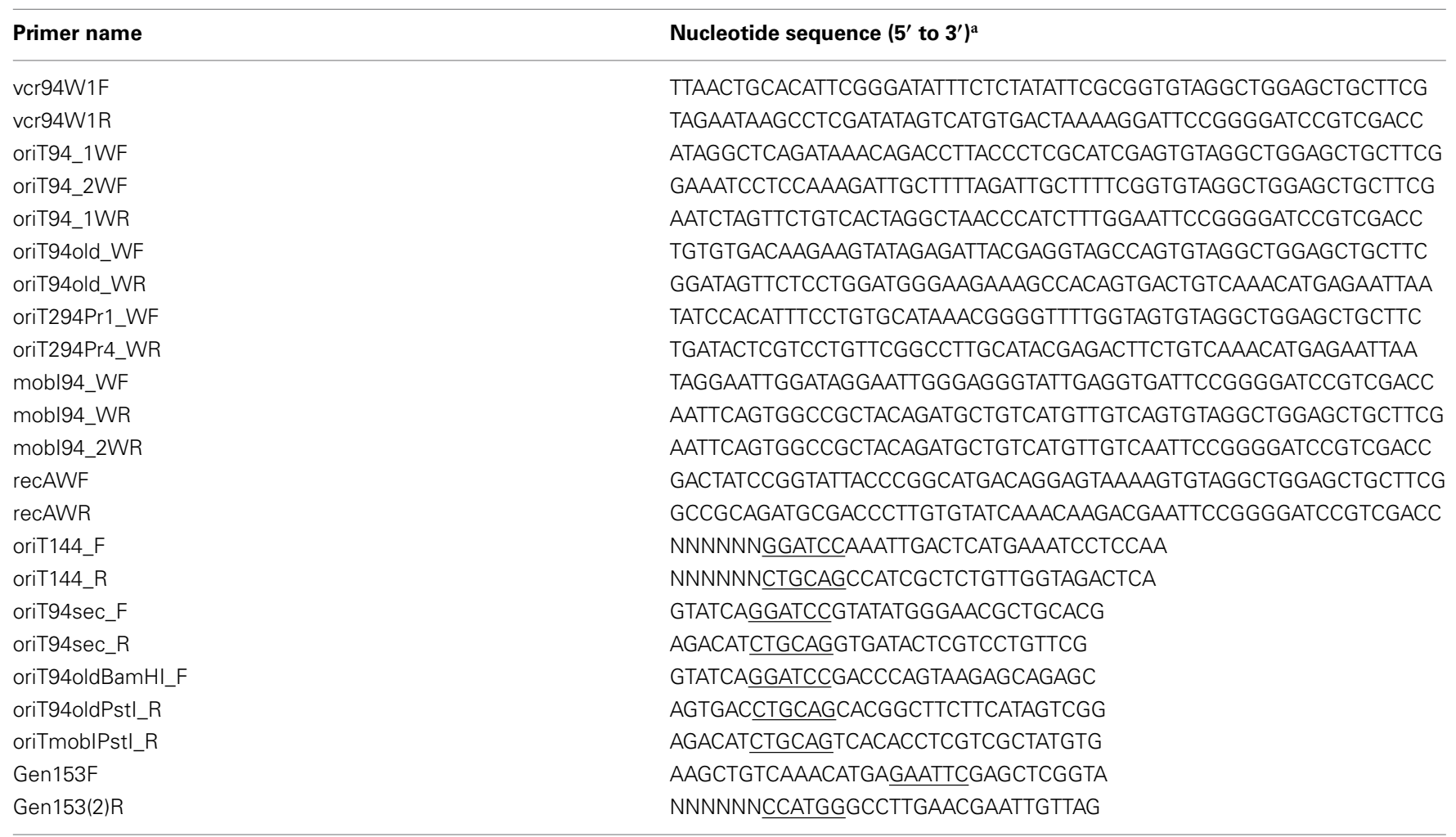

${ }^{a}$ Restriction sites are underlined.

resistance cassette of pAH153 (Haldimann and Wanner, 2001) using primer pair Gen153F/Gen153(2)R, digestion of the resulting fragment using EcoRI and NcoI, and subsequent cloning into pSIM5 (Datta et al., 2006) digested with the same enzymes.

Plasmids used for complementation and mobilization assays containing oriT (pMA1), oriT-vcrx001 (pMA5), and vcrx062 (pMA2) were constructed in pACYC177. Fragments to be cloned were amplified using primers oriT144_F/oriT144_R (oriT), oriT144_F/oriTmobIPstI_R (oriT-vcrx001), and oriT94oldBamHI_F/oriT94oldPstI_R (vcrx062), respectively. Both inserts and vector were digested with BamHI and PstI, and ligated together by T4 DNA ligase reaction. Resulting plasmids were verified using restriction profiles and sequencing.

\section{CONSTRUCTION OF CHROMOSOMAL DELETIONS AND TARGETED DELETIONS IN pVCR94}

Deletion mutants were constructed using the one-step chromosomal gene inactivation technique (Datsenko and Wanner, 2000). All deletions were designed to be non-polar. Primers used are listed in Table 2. The $\Delta \operatorname{rec} A:$ aad7 mutation of $E$. coli VB45 was introduced in E. coli BW25113 using primer pair recAWF/recAWR and pVI36 as a template. Deletion of the MDR region located between $v c r x 028$ and $v c r x 029$ of pVCR94 was constructed in E. coli VB261 using primer pair vcr94W1F/vcr94W1R and pVI36 as template. The $\lambda$ Red recombination system was expressed using pMS1 as described for the pSIM expression vectors (Datta et al., 2006). The $\mathrm{Sp}^{\mathrm{R}}$ cassette was removed from the resulting construction (pVCR94 $\triangle \mathrm{X}:$ :aad7) by Flp-catalyzed excision using the pCP20 vector (Cherepanov and Wackernagel, 1995). The resulting strain containing pVCR94 $\triangle X$ (VB557) was used for subsequent deletions of ori $_{1}$, ori $T_{2}, v c r x 062, v c r x 001$, and ori $T_{2}-v c r x 001$ using primer pairs oriT94_1WF/oriT94_1WR, oriT94_2WF/oriT94_1WR, oriT94old_WF/oriT94old_WR, mobI94_WF/mobI94_WR, and oriT94_2WF/mobI94_2WR, respectively. pVI36 and pSIM5 were used for all these constructions. All deletions were verified by PCR and antibiotic resistance profiling.

\section{SEQUENCING AND SEQUENCE ASSEMBLY OF pVCR94 $\Delta \mathrm{X}$}

Using genomic DNA of E. coli MG1655 $\mathrm{Rf}^{\mathrm{R}}$ harboring pVCR94 or pVCR94 $\Delta X$, Illumina sequencing libraries were prepared as previously described (Rodrigue et al., 2010), and sequenced using 100 -bp paired-end reads. The resulting sequences were assembled using version 2.6 of the de novo gsAssembler (Newbler) software by first removing sequences fully mapping to the E. coli MG1655 genome. The contigs were combined by using PCR and Sanger sequencing reactions. The resulting $\mathrm{pVCR} 94 \Delta \mathrm{X}$ sequence was annotated using the RAST automated pipeline (Aziz et al., 2008), manually curated and submitted to Genbank under accession KF551948.

\section{BLAST ATLAS REPRESENTATION OF SEQUENCES COMPARISON}

A circular BLAST Atlas was computed by GView (Petkau et al., 2010) on the GView server (https://server.gview.ca/) for each sequenced IncA/C plasmid using the BlastN algorithm and mapped against pVCR94 $\triangle X$. Sequences were aligned using raw 
sequence data, with an expect value cutoff of $1 \times 10^{-10}$, an alignment length cutoff of 100, and a percent identity cutoff of $75 \%$. Accession number of the sequences are as follow: pVmi603 (ACYU01000017.1), pIP1202 (NC_009141.1), pYR1 (CP000602.1), pRA1 (NC_012885.1), pR148 (NC_019380.1), pR55 (NC_016976.1), pNDM-KN (NC_019153.1), LS6 (JX442976.1), $\quad$ pNDM100469 (JN861072.1), $\quad$ pKPHS3 (CP003225.1), pSN254 (CP000604.1), pSD_174 (JF267651.1), pAM04528 (NC_012693.1), pPG010208 (NC_019065.1), pAPEC1990_61 (NC_019066.1), pAR060302 (NC_019064.1), pUMNK88 (NC_017645.1), pNDM-1_Dok01 (NC_018994.1), pNDM10505 (JF503991.1), pNDM102337 (JF714412.2), pEH4H (NC_012690.1), pMR2011 (JN687470.1), pTC2 (JQ824049.1), pP99-018 (AB277723.1), pP91278 (AB277724.1), $\quad$ pXNC1 (FN667743.1).

\section{RESULTS}

\section{THE 1994 RWANDAN CHOLERA OUTBREAK INVOLVED A MULTIRESISTANT $V$. cholerae ISOLATE HARBORING A CONJUGATIVE PLASMID}

V. cholerae F1939 is a co-trimoxazole-resistant O1 El Tor clinical isolate recovered from a refugee camp during the 1994 Rwanda cholera outbreak (O'shea et al., 2004a,b). F1939 was initially identified as a strain capable of transferring the co-trimoxazole resistance to $V$. cholerae E4 (Table 1). As such, we expected that the resulting exconjugant, $V$. cholerae BI144, would carry an ICE of the SXT/R391 family, which are major vectors of co-trimoxazole resistance in epidemic $V$. cholerae strains. All our attempts to PCR amplify markers typical of SXT/R391 ICEs (int SXT $_{\text {and }}$ setR) from genomic DNA of BI144 failed (data not shown). Instead, plasmid typing based on PCR amplification of repA revealed that in the exconjugant $V$. cholerae BI144 co-trimoxazole resistance was conferred by a plasmid of the IncA/C group that we named pVCR94 (plasmid Vibrio cholerae Rwanda 1994).

\section{pVCR94 DISSEMINATES MULTIDRUG RESISTANCE AT HIGH FREOUENCIES}

To further characterize pVCR94, mating experiments were carried out to transfer the plasmid from $V$. cholerae BI144 to E. coli VB111 and VB112 strains (MG1655 $\mathrm{Nx}^{\mathrm{R}}$ and MG1655 $\mathrm{Rf}^{\mathrm{R}}$, respectively) by co-trimoxazole selection. As expected, since IncA/C plasmids have a broad host-range, pVCR94 efficiently transferred to and was stably maintained in E. coli, giving rise to NC213 and NC207, respectively. Additional antibiotic resistance testing of $E$. coli exconjugants revealed that pVCR94 also confers resistance to ampicillin, streptomycin, tetracycline, and chloramphenicol, but not to gentamycin, kanamycin, rifampicin, nalidixic acid, and erythromycin (Table 3).

Preliminary tests showed that pVCR94 self-transfers at high frequency. To evaluate its potential to disseminate MDR, tetracycline and chloramphenicol resistance markers were used to test conjugative transfer of pVCR94 among and between E. coli and $V$. cholerae. Intraspecific transfer of pVCR94 was first tested from its primary host $V$. cholerae. Two El Tor variants were used, NC212 (N16961 containing pVCR94) as the donor and E4 as the recipient, revealing that $\mathrm{pVCR} 94$ transfers at very high frequency $\left(\sim 3 \times 10^{-1}\right.$ exconjugant per recipient) (Figure 1). For intraspecific transfer of pVCR94 in E. coli, otherwise isogenic $\mathrm{Nx}^{\mathrm{R}}$ and $\mathrm{Rf}^{\mathrm{R}}$ MG1655 derivative strains VB111 and VB112 were used. Despite a $\sim 6$-fold reduction of transfer, pVCR94 still transferred very efficiently under these conditions (Figure 1). Interspecific transfer of pVCR94 using V. cholerae NC212 as a donor and E. coli VB111 as a recipient and vice versa, E. coli NC208 as a donor and V. cholerae N16961 as a recipient, occurred at roughly the same frequency $\left(\sim 10^{-2}\right.$ exconjugant per recipient cell) (Figure 1).

\section{pVCR94 SHARES A COMMON BACKBONE WITH InCA/C PLASMIDS}

Genomic DNA of E. coli NC207 (VB112 harboring pVCR94) was extracted to sequence the plasmid using the Illumina technology.

Table 3 | Minimal inhibitory concentrations (MIC) of 12 antibiotics against $E$. coli carrying pVCR94 or its $\Delta \mathrm{X}$ mutant.

\begin{tabular}{|c|c|c|c|c|c|c|}
\hline \multirow[b]{2}{*}{ Antibiotic } & \multicolumn{2}{|c|}{ VB111 } & \multicolumn{2}{|c|}{ NC213 (VB111 pVCR94) } & \multicolumn{2}{|c|}{ NC367 (VB111 pVCR94AX) } \\
\hline & $\begin{array}{c}\text { MIC } \\
(\mu \mathrm{g} / \mathrm{mL})^{\mathrm{a}}\end{array}$ & Phenotype $^{b}$ & $\begin{array}{c}\text { MIC } \\
(\mu / m L)^{a}\end{array}$ & Phenotype $^{b}$ & $\begin{array}{c}\text { MIC } \\
(\mu \mathrm{g} / \mathrm{mL})^{\mathrm{a}}\end{array}$ & Phenotype $^{b}$ \\
\hline Ampicillin & $<3.125$ & S & >3200 & $\mathrm{R}$ & $<3.125$ & S \\
\hline Chloramphenicol & 5 & S & 320 & $\mathrm{R}$ & 10 & S \\
\hline Erythromycin & 100 & S & 100 & S & 100 & S \\
\hline Gentamycin & 5 & S & 2.5 & S & 5 & S \\
\hline Kanamycin & 6.25 & S & 6.25 & S & 6.25 & $\mathrm{~S}$ \\
\hline Nalidixic acid ${ }^{c}$ & $<5$ & S & $<5$ & S & nd & S \\
\hline Rifampicin & nd & S & nd & S & nd & S \\
\hline Streptomycin & 12.5 & S & $>6400$ & $\mathrm{R}$ & 12.5 & S \\
\hline Spectinomycin & 25 & S & 25 & S & 25 & S \\
\hline Sulfamethoxazole & nd & S & 1280 & $\mathrm{R}$ & 1280 & $\mathrm{R}$ \\
\hline Tetracycline & 3 & S & 384 & $\mathrm{R}$ & 3 & S \\
\hline Trimethoprim & $<1$ & S & 1024 & $\mathrm{R}$ & $<1$ & S \\
\hline
\end{tabular}

${ }^{a}$ nd, not determined, test was only done on solid agar plate. All assays were carried out in three independent replicates.

${ }^{b} R$, resistant; $S$, susceptible.

${ }^{c}$ These assays were carried out using the RfR derivatives VB112, NC207 (VB112 pVCR94) and NC222 (VB112 pVCR94AX), respectively. 


$\begin{aligned} & \text { Donor } \\ & \text { V. cholerae } \mathrm{NC212}\end{aligned}$
E. coli $\mathrm{NC207}$

A draft assembly generated a sequence of $134,484 \mathrm{bp}$. Initial sequence analyses revealed the presence of only three resistance genes, sul1, sul2, and $d f r A 15$, conferring resistance to cotrimoxazole. sul1 and $d f r A 15$ belong to a class 1 mobile integron devoid of any other integron cassette (Figure 2) Identical integron structures have already been described in clinical $V$. cholerae strains belonging to non-O1, non-O139 serogroups isolated in the mid-90s in Thailand and India (Dalsgaard et al., 2000b; Thungapathra et al., 2002). Further analysis confirmed that the sequence of pVCR94 was partial; a segment of unknown size overlapping most other antibiotic resistance genes could not be properly assembled. We constructed a deletion mutant, pVCR94 $\Delta \mathrm{X}$, which lacks this region (see below), and submitted the resulting 120,572-bp sequence to Genbank database (accession number KF551948) (Figure 3A).

Comparative genomics confirmed the conservation in pVCR94 $\triangle \mathrm{X}$ of the large core set of genes that are common to all members of the IncA/C group (Figure 3B), including genes that may be involved in the regulation of IncA/C conjugative transfer (Table 4). Among them, vcrx148 and vcrx149 are particularly interesting. Pfam analyses (database v27.0) revealed that the Vcrx149 protein contains an FlhC signature (Pfam PF05280) whereas Vcrx148 has very weak homology with the FlhD domain (Pfam PF05247). Sequence comparisons also brought to light variable regions encoding hypothetical proteins of unknown function (VR2, VR3, VR4, VR5, and VR6) (Figure 3). The 4.5-kb

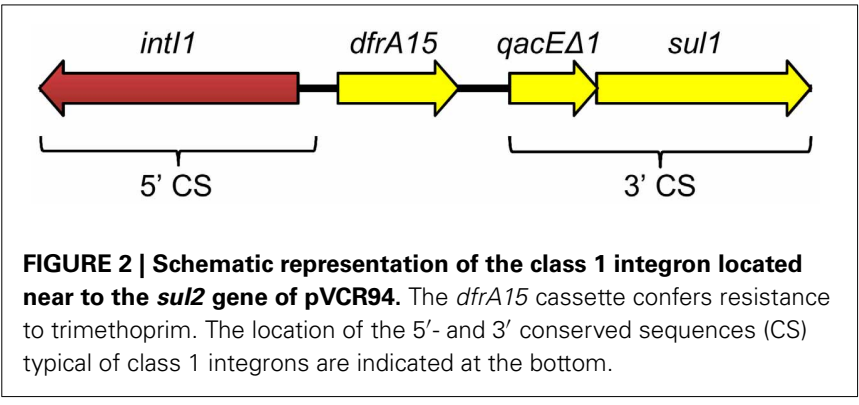

variable region VR1 contains DNA that is only found in pVCR94 and codes for a putative cadmium-bromine pump efflux and its cognate regulator ( $v$ crx049, Table 4) along with a transposase gene. The 1.5-kb VR7 region codes for a putative transmembrane protein with an EndoU_bacteria nuclease domain (Pfam PF14436) and is predicted to be a secreted bacterial toxin (Zhang et al., 2011).

Interestingly, comparison of the genes found in variable regions of pVCR94 with those of other sequenced IncA/C plasmids indicate that pVCR94 is more closely related to plasmids recovered from $P$. damselae (pP91278 and pP99-018), K. pneumoniae (pR55), E. coli (pPG010208), and P. stuartii (pTC2) than from the plasmid identified in V. mimicus (pVmi603) (Figure 3).

\section{pVCR94 $\triangle \mathrm{X}$, A CONVENIENT PROTOTYPE FOR THE STUDY OF THE BASIC BIOLOGY OF IncA/C PLASMIDS}

To facilitate future studies of IncA/C plasmid biology without the challenges and limitations associated with the MDR phenotype usually conferred by these mobile elements, we decided to construct a mutant of pVCR94 coding for a reduced set of antibiotic resistance. Antibiotic resistance markers carried by vectors used for expression of $\lambda$ Red recombination system, $A p^{R}$ for pKD46 and $\mathrm{Ap}^{\mathrm{R}}, \mathrm{Cm}^{\mathrm{R}}, \mathrm{Kn}^{\mathrm{R}}$, or $\mathrm{Sp}^{\mathrm{R}}$ for $\mathrm{pSIM}$ vectors (Datsenko and Wanner, 2000; Datta et al., 2006), are not compatible with pVCR94 and most known IncA/C plasmids. To circumvent this problem, we constructed a $\mathrm{Gn}^{\mathrm{R}}$ derivative of pSIM5 (pMS1) to allow expression of $\lambda$ Red recombination function in this multiple antibiotic resistance context.

Using pMS1 and a $\mathrm{Sp}^{\mathrm{R}}$ cassette, we deleted the large fragment containing the MDR-conferring genes in pVCR94 and located between vcrx028 and vcrx029 (sul2), which encode a hypothetical protein and resistance to sulfamethoxazole respectively. After elimination of the $\mathrm{Sp}^{\mathrm{R}}$ cassette, antibiotic resistance examination confirmed the sensitivity of E. coli MG1655 containing pVCR94 $\Delta \mathrm{X}$ (NC367) to all tested antibiotics but sulfamethoxazole (Table 3). Despite the large deletion, pVCR94 $\Delta \mathrm{X}$ was able to stably maintain in E. coli. Finally, mating experiments showed that pVCR94 $\Delta \mathrm{X}$ remains self-transmissible at the same frequency as wild-type pVCR94 (Figure 1). Although the exact gene content and size of the region that was deleted remains to be established, our functional tests indicate that pVCR94 $\triangle \mathrm{X}$ now constitutes a convenient prototype for in-depth molecular study of pVCR94 and related IncA/C plasmids. 
A
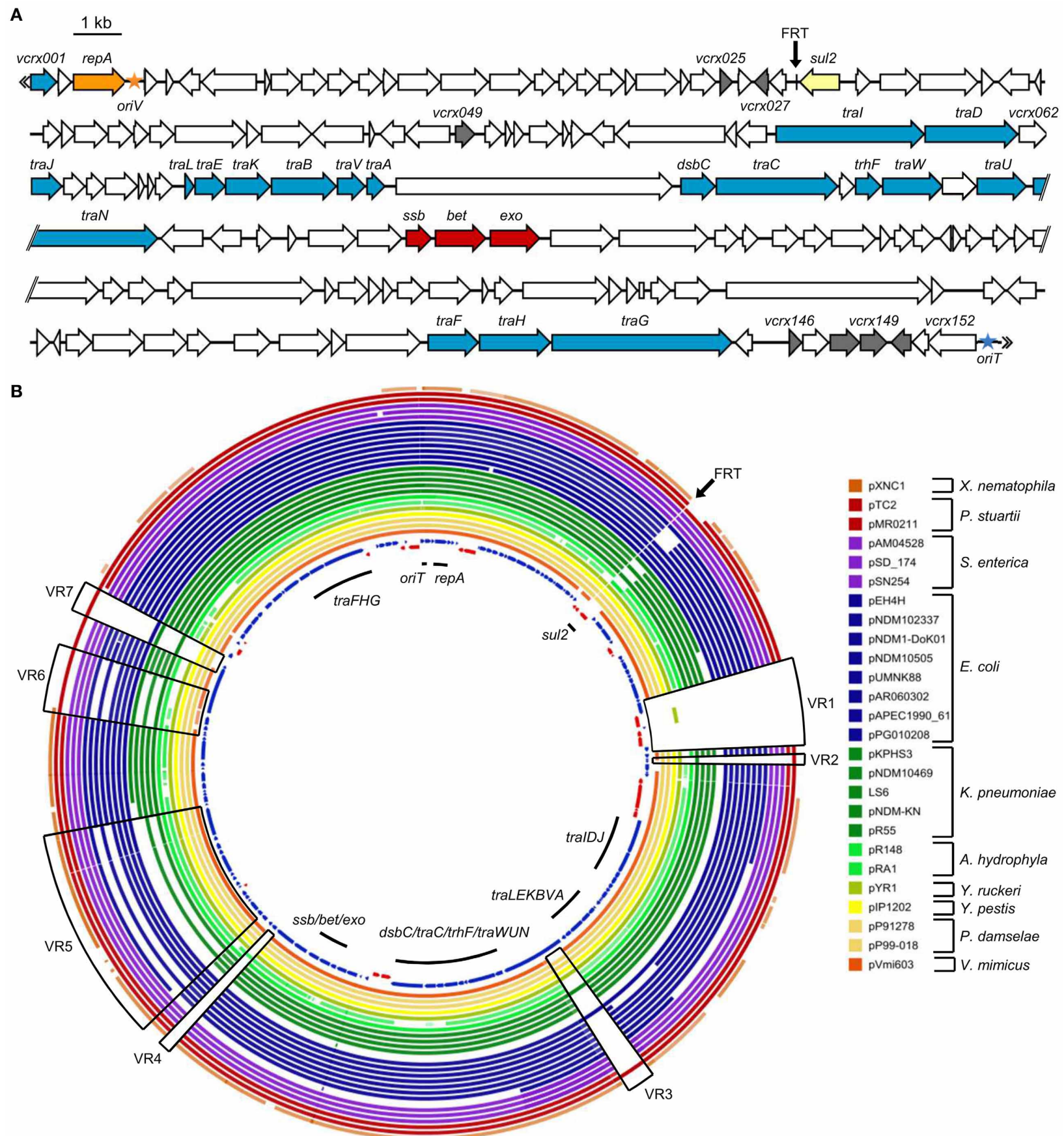

FIGURE 3 | Sequence analysis of pVCR94 $\mathbf{X}$. (A) Schematic representation of the genetic organization of pVCR94 $\Delta \mathrm{X}$. The location and orientation of ORFs are indicated by arrowed boxes. The color of the arrowed boxes depicts the putative function or relationships of each ORF deduced from functional analyses and BLAST comparisons: white, unknown function; blue, conjugative transfer; orange, replication; yellow, antibiotic resistance; gray, regulation; red, homologous recombination. The origin of replication (oriV) and the origin of transfer (oriT) are symbolized by an orange and a blue star, respectively. The position of the scar resulting from the deletion of the multidrug resistance gene cluster is indicated (FRT site). (B) Genetic comparison of pVCR94 $\Delta \mathrm{X}$ and other sequenced IncA/C plasmids. A BLAST Atlas was constructed with the pVCR94 $\Delta \mathrm{X}$ sequence set as the reference (innermost circle). All completely sequenced IncA/C plasmids available in
Genbank were aligned according to their raw sequence data toward pVCR94 $\Delta \mathrm{X}$ using a BlastN algorithm. Coding sequences of pVCR94 $\Delta \mathrm{X}$ appear on the innermost circle in blue for the positive strand, and red for the negative strand. All other aligned plasmids sequences are represented only according to their sequence homology toward the reference. Full color saturation represents $100 \%$ sequence identity, and gaps indicate regions of divergence $(<75 \%$ percentage of nucleic acid identity). The black arrow indicates the position of the deletion that generated pVCR94 $\Delta \mathrm{X}$. Part of an IncA/C plasmid closely related to pVCR94 was detected among at least 3 different contigs of the unassembled V. cholerae RC9 genome (Genbank accession number $\mathrm{ACHX00000000).} \mathrm{Since} \mathrm{the} \mathrm{sequence} \mathrm{of} \mathrm{this} \mathrm{plasmid} \mathrm{is}$ not assembled and probably not complete, it was not included in this analysis. 
Table 4 | Open reading frames (ORFs) of pVCR94 $\Delta X$ coding for putative transcriptional regulators.

\begin{tabular}{|c|c|c|c|c|c|}
\hline ORF name & Size $(a a)^{a}$ & Predicted function & $\begin{array}{l}\text { Most significant } \\
\text { Pfam matches }\end{array}$ & $\begin{array}{c}\text { Conserved in } \\
\text { IncA/C plasmids }\end{array}$ & $\begin{array}{l}\text { Ortholog expressed } \\
\text { in pAR060302 }\end{array}$ \\
\hline vcrx025 & 90 & HUß-like DNA-binding protein & Bac_DNA_binding (PF00216) & Yes & + \\
\hline vcrx049 & 135 & $\begin{array}{l}\mathrm{Cd}(\mathrm{II}) / \mathrm{Pb}(\mathrm{II}) \text {-responsive } \\
\text { transcriptional regulator }\end{array}$ & MerR_1 (PF13411) & No & Absent \\
\hline vcr $\times 148$ & 202 & $\begin{array}{l}\text { FlhD-like transcriptional } \\
\text { activator }\end{array}$ & FlhD $(\mathrm{PF} 05247)^{c}$ & Yes & 0 \\
\hline vcr $\times 149$ & 183 & $\begin{array}{l}\text { FlhC-like transcriptional } \\
\text { activator }\end{array}$ & FIhC (PF05280) & Yes & 0 \\
\hline vcr $\times 150$ & 139 & H-NS-like DNA-binding protein & Histone_HNS (PF00816) & Yes & ++ \\
\hline
\end{tabular}

a Size in amino-acids of the predicted translation product.

${ }^{b}$ Level of expression of ortholog genes in the IncA/C plasmid pAR060302 (Lang et al., 2012).

${ }^{c}$ This domain was reported as an insignificant Pfam-A match.

\section{IDENTIFICATION OF oriT IncA/C, THE ORIGIN OF TRANSFER OF IncA/C PLASMIDS}

Conjugative transfer is initiated at a specific cis-acting locus called the origin of transfer (oriT) by a DNA relaxase, which is typically called TraI. Fricke et al. (2009) and Welch et al. (2007) proposed to position the oriT locus of IncA/C plasmids (ori $T_{\text {IncA/C }}$ ) between the genes traD and traJ. This annotation was based not on experimental data but rather on an analogy with the location of oriT of the ICE SXT proposed by Beaber et al. (2002). However, the sequence located between traD and traJ in SXT has been shown to be unable to support the mobilization of a non-mobilizable plasmid and oriT of the SXT/R391 ICEs was subsequently relocated upstream of a gene named mobI (Ceccarelli et al., 2008). Therefore, we hypothesized that the region located between traD and traJ in IncA/C plasmids, which contains vcrx062 in pVCR94 $\Delta \mathrm{X}$, is not ori $T_{\text {IncA/C }}$ and experimentally investigated the location of the ori $_{\text {IncA/C }}$ in our model. Noteworthy in the following experiments, the use of alternative donor and recipient strains caused a tenfold reduction in transfer of $\mathrm{pVCR} 94 \Delta \mathrm{X}$ compared to the previous experiments (Figures 1, 4A), thereby suggesting that the genetic background has a notable influence on the efficiency of IncA/C plasmids transfer.

First, we verified whether the region containing vcrx062 was required for transfer and whether it was sufficient to support the mobilization of the non-mobilizable low-copy plasmid pACYC177. We used as a donor E. coli MS2, which harbors pVCR94 $\Delta \mathrm{X} \Delta v \operatorname{cr} x 062\left(\mathrm{Sp}^{\mathrm{R}}\right)$, to mobilize a pACYC177 derivative containing $v c r x 062\left(\mathrm{pMA} 2, \mathrm{Kn}^{\mathrm{R}}\right)$ to the $\mathrm{Tc}^{\mathrm{R}}$ strain E. coli CAG18439. Exconjugants were independently selected for acquisition of pMA2 $\left(\mathrm{Tc}^{\mathrm{R}} \mathrm{Kn}^{\mathrm{R}}\right)$ or pVCR94 $\Delta \mathrm{X} \Delta v \operatorname{vrx} 062\left(\mathrm{Tc}^{\mathrm{R}} \mathrm{Sp}^{\mathrm{R}}\right)$. We observed that deletion of vcrx062 did not affect the transfer efficiency of pVCR94 $\Delta \mathrm{X}$ (Figures 4AI,II). Furthermore, the $v c r x 062$ locus was incapable to initiate transfer of pMA2 as no $\mathrm{Tc}^{\mathrm{R}}$ $\mathrm{Kn}^{\mathrm{R}}$ exconjugant could be recovered (Figure 4AII). These results provide convincing evidence that the locus located between traD and traJ is not an oriT for IncA/C plasmids. Interestingly, in the presence of $\mathrm{pMA} 2$, transfer of pVCR94 $\Delta \mathrm{X}$ dropped significantly. This phenotype was not observed in the presence of pACY177.

In the ICEs of the SXT/R391 family, oriT is located in a large intergenic region between two divergent genes: mobI, which is crucial for conjugative transfer, and s003, a gene of unknown function (Ceccarelli et al., 2008). Comparison of the s003-mobI locus of SXT with the corresponding region of pVCR94 revealed striking similarities in gene organization (Figure 4B). In fact, in pVCR94 vcrx001 encodes a protein sharing a weak identity with MobI (Figure 4C) and vcrx152 encodes a protein sharing $58 \%$ identity with $\mathrm{S} 003$. To test whether ori $_{\text {IncA/C }}$ was located between $v c r x 152$ and $v c r 001$, plasmid pMA1 $\left(\mathrm{Kn}^{\mathrm{R}}\right)$ was constructed by cloning this intergenic region (putative oriT) into pACYC177 (Figure 4D). pMA1 was subsequently introduced into E. coli MS1 and MS5, two $\mathrm{Sp}^{\mathrm{R}}$ strains containing pVCR94 $\Delta \mathrm{X}$ $\Delta$ ori $_{1}$ or $\Delta \operatorname{oriT}_{2}$, respectively (Figure 4D). In both of these mutants, deletions were designed to preserve the promoter region upstream of vcrx001. We observed that while neither deletion abolished the transfer of pVCR94, both led to a significant 10fold reduction of transfer (Figures 4AIII,IV). In addition, while mobilization of pACYC177 by pVCR $94 \Delta \mathrm{X} \Delta$ ori $_{1}$ or $\Delta$ ori $_{2}$ was undetectable, pMA1 was mobilized at a frequency of $1.3 \times 10^{-5}$ to $4.0 \times 10^{-5}$ exconjugant per donor cell (Figures 4AIII,IV). Altogether, these results suggest the presence of an oriT between $v c r \times 152$ and $v c r x 001$ in pVCR94 $\Delta \mathrm{X}$ as this locus is a weak yet suitable substrate for transfer initiation. However, the low efficiency of mobilization conferred by this locus and the ability of the $\Delta$ ori $_{2}$ mutant of pVCR94 $\Delta \mathrm{X}$ to transfer efficiently suggest that other alternative oriT loci may exist in IncA/C plasmids. Alternatively, the actual oriT may also include the promoter region of $v$ crx 001 and perhaps the $5^{\prime}$ end this open reading frame (see below).

\section{vcrX001 IS AN ESSENTIAL GENE FOR CONJUGATIVE TRANSFER OF IncA/C PLASMIDS}

Transfer of SXT is abolished in the absence of MobI, a protein that is likely an auxiliary component of the relaxosome (Ceccarelli 


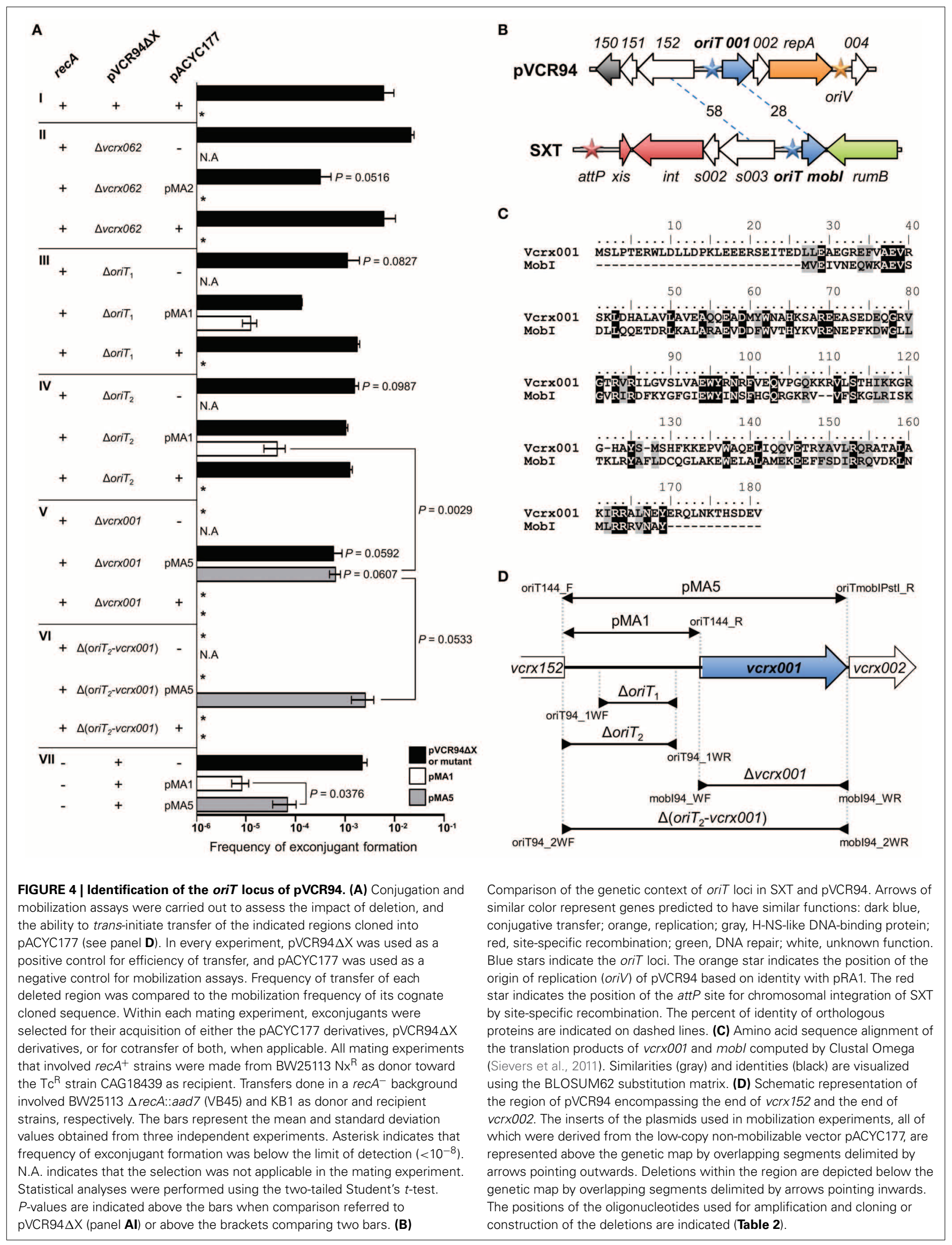


et al., 2008). MobI of SXT/R391 ICEs exhibits 28\% identity (40\% similarity) with its IncA/C ortholog $v c r x 001$ (Figures 4B,C). Annotated in all available IncA/C plasmids sequences as a gene coding for a hypothetical protein, the importance of vcrx001 in conjugative transfer of these plasmids has never been investigated. Furthermore, the low frequency of mobilization of pMA1 observed above could be due to the lack of an adjacent mobI-like gene as it has already been reported for SXT (Ceccarelli et al., 2008).

We constructed E. coli MS3, which harbors pVCR94 $\Delta \mathrm{X}$ $\Delta v c r x 001\left(\mathrm{Sp}^{\mathrm{R}}\right)$, to test the importance of the mobI ortholog for IncA/C transfer. As reported for SXT $\Delta m o b I$, transfer of the $\Delta v c r x 001$ mutant of pVCR94 $\Delta \mathrm{X}$ was completely abolished (Figure 4AV), confirming the essential role of vcrx001 in conjugative transfer. To further investigate its function, the 1063-bp fragment overlapping $v c r \times 001$ and the upstream intergenic region was cloned into pACYC177 to generate pMA5 (Figure 4D). Mating experiments using pMA5 were carried out to evaluate the impact of the cis-expression of $v c r x 001$ on a mobilizable plasmid con-

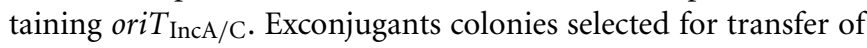
pMA5 or pVCR94 $\Delta \mathrm{X} \Delta v c r x 001$ were recovered at a frequency of $1 \times 10^{-3}$, which is not dramatically different from transfer of pVCR94 $\triangle \mathrm{X}$ (Figure 4AV). Thus, abolition of transfer observed in the $\Delta v c r x 001$ mutant is not due to a polar effect of the deletion on expression of the repA gene, as it can be complemented by expression from its endogenous promoter on a plasmid. Furthermore, the presence of $v c r x 001$ in cis significantly improved the transfer of pMA5 over pMA1 (10-fold increase).

Since pVCR94 $\Delta \mathrm{X} \Delta v c r x 001$ and pMA5 share an identical 514-bp fragment corresponding to the vcrx152-vcrx001 intergenic region, we tested whether the mobilization observed for pMA5 could result from cointegrate formation between the two plasmids mediated by homologous recombination. We used two complementary approaches to test this hypothesis. First to rule out the RecA-mediated recombination, mobilization of pMA1 and pMA5 by pVCR94 $\triangle \mathrm{X}$ was tested using $\triangle \mathrm{rec} A$ donor and recipients strains (E. coli $\mathrm{VB} 45$ and $\mathrm{KB} 1$, respectively). Results showed that transfer of pVCR94 $\triangle \mathrm{X}$ is RecA-independent and that pMA5, as well as pMA1, were still mobilized in this $\operatorname{rec} A$ background, with the same 10 -fold improvement due to the presence of $v c x r 001$ in pMA5 (Figure 4AVII). Second, since homologous recombination could also potentially be mediated by the activity of the putative $\lambda$ Red recombination system carried by IncA/C plasmids ( $s s b$, bet, exo, see Figure 3A) we constructed a $\Delta$ (ori $T_{2}$-vcrx001) mutant of pVCR94 $\Delta \mathrm{X}$ devoid of homologous sequence in pMA5, thereby resulting in E. coli MS6 (Figure 4D). pVCR94 $\Delta \mathrm{X} \Delta\left(\right.$ oriT $\left._{2}-v c r x 001\right)$ was no longer able to transfer and this mutation was not complemented by expression of $v c r x 001$ from pMA5, thereby confirming that ori $_{\text {IncA/C }}$ is located within the deleted fragment (Figure 4AVI). Furthermore pMA5 itself remained mobilizable at very high frequency by pVCR94 $\Delta \mathrm{X}$ $\Delta$ (ori $\left.T_{2}-v c r x 001\right)$, despite the absence of homologous sequences between the two plasmids confirming that the insert of this plasmid contains ori $T_{\text {IncA/C. Interestingly, mobilization of pMA5 was }}$ even improved in this context suggesting that different replicons carrying ori $_{\text {IncA/C }}$ likely compete against with each other during transfer.

\section{DISCUSSION}

Cholera remains one of the most devastating human diseases in the world mainly because of toxicigenicity, transmissibility, the rapid multiplication of $V$. cholerae in favorable conditions, and the MDR phenotype of pandemic and epidemic strains. In most modern cholera outbreaks, MDR has been shown to be conferred by SXT/R391 ICEs (for review, Garriss and Burrus, 2013). In the present study, we described the IncA/C plasmid pVCR94 recovered from the multidrug-resistant strain $V$. cholerae $\mathrm{O} 1 \mathrm{El}$ Tor F1939 as the element most likely responsible for the cotrimoxazole resistance during the severe 1994 cholera epidemics in Rwanda. This conclusion is further supported by the absence of the ICE SXT from two other co-trimoxazole resistant $V$. cholerae O1 El Tor isolates, F1873 and F1875, recovered from Rwandan refugees in the summer of 1994 in Goma, Democratic Republic of the Congo (Waldor et al., 1996). Mating assays showed that pVCR94 is a high-efficiency driver of antibiotic resistance dissemination between $V$. cholerae strains as well as to and from $E$. coli. Studies carried out on Asian pandemic isolates of $V$. cholerae underline the rapid emergence and dissemination of IncA/C plasmids as key drivers of antibiotic resistance between 1994 and 2000 (Pan et al., 2008). Although the rate of dissemination of SXT/R391 ICEs between vibrios is rather low in the laboratory as their transfer frequency rarely exceeds $1 \times 10^{-5}$ in intra-species mating experiments (Waldor et al., 1996; Burrus et al., 2006b; Osorio et al., 2008), these elements have been extremely successful in invading environmental and clinical $V$. cholerae in the past two decades (Chin et al., 2011; Mutreja et al., 2011; Yu et al., 2012; Garriss and Burrus, 2013; Katz et al., 2013). On the contrary, IncA/C plasmids such as pVCR94 are much more efficient $\left(1 \times 10^{-1}\right)$ and seem to transfer even better between vibrios than in E. coli. It has recently been shown that pVCR94 transfers at high frequency between $E$. coli strains in sludge resulting from the coagulation/flocculation treatment of surface water, reaching the highest frequency after $72 \mathrm{~h}$ with about $1 \times 10^{-2}$ exconjugants per recipient cell (Pariseau et al., 2013). These observations indicate that, in laboratory conditions as well as in a simulated environmental setting, pVCR94 is a very efficient conjugative plasmid able to invade a significant proportion of the surrounding compatible cells. Knowing the prevalence of IncA/C plasmids in pathogenic bacteria isolated from humans and food-producing animals, their circulation in clinical and environmental $V$. cholerae isolates is worrisome and their impact on the emergence of new pathogenic isolates needs to be surveyed.

Until now, relatively little has been done to characterize the basic biology of IncA/C plasmids despite the significant threat that they represent in the war against MDR pathogenic bacteria. In fact, one of the major challenges encountered to genetically manipulate IncA/C plasmids is their propensity to confer MDR to their host. As a consequence, the majority of antibiotic resistance phenotypes conferred by molecular engineering tools (plasmids, selection gene cassettes) are also conferred by IncA/C plasmids. A gentamycin-resistant version of a $\lambda$ Red recombination expression plasmid that is compatible with pVCR94 allowed us to construct pVCR94 $\triangle \mathrm{X}$, a derivative lacking the MDR region. Sequence analyses and experimental evidences revealed that $\mathrm{pVCR} 94 \Delta \mathrm{X}$ carries the core sequences necessary for self-transfer and maintenance 
of IncA/C plasmids. Using this plasmid as a convenient prototype for the study of IncA/C biology, we have identified the locus

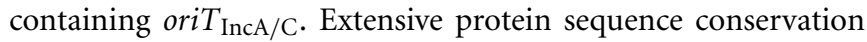
and gene synteny between IncA/C plasmids and SXT/R391 ICEs were crucial in this process. We also showed that vcrx001, the ortholog of mobI of SXT, plays a key role in transfer and enhances the mobilization of a plasmid containing ori $T_{\text {IncA/C }}$ when it is located on the same replicon. In SXT, mobI was reported to be a cis-acting sequence coding for a putative auxiliary component of the relaxosome required for SXT transfer (Ceccarelli et al., 2008). Surprisingly, deletion of the center $\left(\Delta o r i T_{1}\right)$ and the left part $\left(\Delta \operatorname{ori}_{2}\right)$ of the intergenic region between $v$ crx152 and $v$ crx001 did not affect much the transfer of pVCR94. This suggests that ori $_{\text {IncA/C }}$ overlaps the right part of this intergenic region and perhaps the $5^{\prime}$ end of $v c r x 001$. Experiments aimed at discovering the minimal oriT sequence required for initiation of transfer of IncA/C plasmids are ongoing. Furthermore, the mutation $\Delta \mathrm{oriT}_{2}$ which removed the promoter upstream of $v c r x 152$ likely prevents expression of three genes, two of unknown function (vcrx152 and $v$ cr $x 151)$ and one coding for a predicted H-NS-like protein (vcrx150) (Table 2). H-NS-like proteins encoded by conjugative plasmids have been shown to provide stealth function helping the transmission of the plasmid into a naive host (Doyle et al., 2007). While the ortholog of vcrx150 was shown to be expressed in the IncA/C plasmid pAR060302 (Lang et al., 2012), our deletion did not seem to alter significantly the stability of pVCR94 or its ability to transfer.

Mobile genetic elements are characterized by a modular structure, each module containing the genes and sequences involved in a same biological function (Toussaint and Merlin, 2002). Clustering is an efficient way to exchange and transfer "en bloc" fully functional modules and thus confers new adaptive traits in one event (Lawrence and Roth, 1996). Previous sequence analyses of IncA/C plasmids highlighted their modular structure, with specific variable regions corresponding to mobile integrons and transposable elements conferring adaptive traits such as multiple antibiotics resistance (Welch et al., 2007; Fricke et al., 2009). As observed for pIP1202 and other IncA/C plasmids, pVCR94 carries a class 1 integron. While this integron carries only a $d f r A 15$ cassette conferring resistance to trimethoprim, its impact should not be underestimated. On one hand, Baharoglu et al. (2010) demonstrated that incoming single-stranded DNA during conjugative transfer triggers the SOS response in the recipient cell, in both $E$. coli and $V$. cholerae. On the other hand, SOS response enhances integron cassette rearrangements through excision/integration, providing opportunities for different integrons present in the same host to exchange cassettes (Guerin et al., 2009). Thus, conjugative transfer of pVCR94 could lead to integron cassettes trapping and drive their dissemination between bacterial communities. Sequence analysis of pVCR94 also revealed the specific region VR1 corresponding to a putative transposon that could confer resistance to heavy metals. This resistance cluster is exclusively carried by the chromosome of various Gram-negative bacteria. Thus, IncA/C plasmids drive horizontal transfer of chromosomal loci and other mobile genetic elements at high frequency by cis-mobilization. Beyond intra- and inter-molecular rearrangements among and between chromosome and plasmid, pVCR94 could also mediate trans-mobilization of genomic islands present in its host range, as demonstrated for the S. enterica pathogenicity island SGI1 (Douard et al., 2010). Finally, two core genes of Inc $A / C$ plasmids code for homologs of $\lambda$ Bet and $\lambda$ Exo proteins of the $\lambda$ Red recombination system. Many conjugative plasmids and ICEs code for such proteins, which have been shown to generate diversity of SXT/R391 ICEs (Garriss et al., 2009, 2013). Similarly, IncA/C plasmids could enhance their plasticity by recombining with a replicon present in the same cell that shares short identical sequences. Altogether, these observations give glimpses of the high dynamics of IncA/C plasmids and their impact on genome plasticity, which could have significant implications for pathogenic bacteria and forecast a bleak future for antibiotherapies.

Many questions remain regarding the coexistence in $V$. cholerae of IncA/C plasmids and SXT/R391 ICEs as two different yet related entities capable of conferring MDR and in particular, resistance to co-trimoxazole. For instance, no single isolate bearing both types of element has been described to date with the exception of isolates from Eastern China that were found to bear both pMRV150-like IncA/C plasmids and SXT-like elements (Pan et al., 2008). Although the IncA/C plasmids in these strains were shown to be able to transfer to recipient cells, no exconjugant bearing also a copy of the SXT-like elements was found, thereby suggesting that the latter were not functional or that negative interference between the two families of mobile elements occurs. Given these observations, we are wondering whether there is a mutual exclusion of IncA/C plasmids and SXT/R391 ICEs. If so, given the relative efficiency of transfer of both types of mobile genetic elements, can we expect to observe a displacement of SXT/R391 ICEs by IncA/C plasmids in clinical and environmental populations of $V$. cholerae in the near future? Given the prevalence of IncA/C plasmids in a plethora of bacteria, their broad host-range and their ability of mobilize MDR-conferring genomic islands, close attention needs to be paid concerning their circulation and evolution. Sequencing of pathogenic isolates bearing IncA/C plasmids and sequences analyses provide valuable information regarding the epidemiology of IncA/C plasmids but molecular characterization of their mechanism of transfer remain unavoidable to unravel the characteristics that make them so successful in modern pathogens. Using pVCR94 $\Delta \mathrm{X}$ as a prototype, it is now easier to explore the biology and regulation of IncA/C plasmids.

\section{ACKNOWLEDGMENTS}

We are grateful to M.K. Waldor for the kind gift of Vibrio cholerae BI144. We thank Alain Lavigueur and Eric Bordeleau for their insightful comments about the manuscript. This work was supported by a Discovery Grant (Vincent Burrus and Sébastien Rodrigue) and Discovery Acceleration Supplement from the Natural Sciences and Engineering Council of Canada (Vincent Burrus), and by a team research project from the Fonds de recherche du Québec - Nature et technologies awarded to Sébastien Rodrigue and Vincent Burrus. Vincent Burrus holds a Canada Research Chair in bacterial molecular genetics and is a member of the FRSQ-funded Centre de Recherche Clinique Étienne-Le Bel. 


\section{REFERENCES}

Aziz, R. K., Bartels, D., Best, A. A., Dejongh, M., Disz, T., Edwards, R. A., et al. (2008). The RAST Server: rapid annotations using subsystems technology. BMC Genomics 9:75. doi: 10.1186/1471-2164-9-75

Baharoglu, Z., Bikard, D., and Mazel, D. (2010). Conjugative DNA transfer induces the bacterial SOS response and promotes antibiotic resistance development through integron activation. PLoS Genet. 6:e1001165. doi: 10.1371/journal.pgen.1001165

Beaber, J. W., Hochhut, B., and Waldor, M. K. (2002). Genomic and functional analyses of SXT, an integrating antibiotic resistance gene transfer element derived from Vibrio cholerae. J. Bacteriol. 184, 4259-4269. doi: 10.1128/JB.184.15.42594269.2002

Bioforce, (1996). [Cholera in Goma, July 1994. Bioforce]. Rev. Epidemiol. Sante Publique 44, 358-363.

Bompangue Nkoko, D., Giraudoux, P., Plisnier, P. D., Tinda, A. M., Piarroux, M., Sudre, B., et al. (2011). Dynamics of cholera outbreaks in Great Lakes region of Africa, 1978-2008. Emerg. Infect. Dis. 17, 2026-2034. doi: 10.3201/eid1711.110170

Bordeleau, E., Brouillette, E., Robichaud, N., and Burrus, V. (2010). Beyond antibiotic resistance: integrating conjugative elements of the SXT/R391 family that encode novel diguanylate cyclases participate to c-di-GMP signalling in Vibrio cholerae. Environ. Microbiol. 12, 510-523. doi: 10.1111/j.14622920.2009.02094.x

Burrus, V., Marrero, J., and Waldor, M. K. (2006a). The current ICE age: biology and evolution of SXT-related integrating conjugative elements. Plasmid 55, 173-183. doi: 10.1016/j.plasmid.2006.01.001

Burrus, V., Quezada-Calvillo, R., Marrero, J., and Waldor, M. K. (2006b). SXT-related integrating conjugative element in New World Vibrio cholerae. Appl. Environ. Microbiol. 72, 3054-3057. doi: 10.1128/AEM.72.4.30543057.2006

Cavallo, J. D., Niel, L., Talarmin, A., and Dubrous, P. (1995). [Antibiotic sensitivity to epidemic strains of Vibrio cholerae and Shigella dysenteriae 1 isolated in Rwandan refugee camps in Zaire]. Med. Trop. (Mars) 55, 351-353.

Ceccarelli, D., Daccord, A., Rene, M., and Burrus, V. (2008). Identification of the origin of transfer (oriT) and a new gene required for mobilization of the SXT/R391 family of integrating conjugative elements. J. Bacteriol. 190, 5328-5338. doi: 10.1128/JB.00150-08

Ceccarelli, D., Salvia, A. M., Sami, J., Cappuccinelli, P., and Colombo, M. M. (2006). New cluster of plasmid-located class 1 integrons in Vibrio cholerae $\mathrm{O} 1$ and a dfrA15 cassette-containing integron in Vibrio parahaemolyticus isolated in Angola. Antimicrob. Agents Chemother. 50, 2493-2499. doi: 10.1128/AAC.01310-05

Ceccarelli, D., Spagnoletti, M., Cappuccinelli, P., Burrus, V., and Colombo, M. M. (2011). Origin of Vibrio cholerae in Haiti. Lancet Infect. Dis. 11, 262. doi: 10.1016/S1473-3099(11)70078-0

Chang, A. C., and Cohen, S. N. (1978). Construction and characterization of amplifiable multicopy DNA cloning vehicles derived from the P15A cryptic miniplasmid. J. Bacteriol. 134, 1141-1156.

Cherepanov, P. P., and Wackernagel, W. (1995). Gene disruption in Escherichia coli: $\mathrm{Tc}^{\mathrm{R}}$ and $\mathrm{Km}^{\mathrm{R}}$ cassettes with the option of Flp-catalyzed excision of the antibiotic-resistance determinant. Gene 158, 9-14. doi: 10.1016/03781119(95)00193-A

Chin, C. S., Sorenson, J., Harris, J. B., Robins, W. P., Charles, R. C., Jean-Charles, R. R., et al. (2011). The origin of the Haitian cholera outbreak strain. N. Engl. J. Med. 364, 33-42. doi: 10.1056/NEJMoa1012928

Dalsgaard, A., Forslund, A., Petersen, A., Brown, D. J., Dias, F., Monteiro, S., et al. (2000a). Class 1 integron-borne, multiple-antibiotic resistance encoded by a 150-kilobase conjugative plasmid in epidemic Vibrio cholerae $\mathrm{O} 1$ strains isolated in Guinea-Bissau. J. Clin. Microbiol. 38, 3774-3779.

Dalsgaard, A., Forslund, A., Serichantalergs, O., and Sandvang, D. (2000b). Distribution and content of class 1 integrons in different Vibrio cholerae O-serotype strains isolated in Thailand. Antimicrob. Agents Chemother. 44, 1315-1321. doi: 10.1128/AAC.44.5.1315-1321.2000

Datsenko, K. A., and Wanner, B. L. (2000). One-step inactivation of chromosomal genes in Escherichia coli K-12 using PCR products. Proc. Natl. Acad. Sci. U.S.A. 97, 6640-6645. doi: 10.1073/pnas.120163297

Datta, S., Costantino, N., and Court, D. L. (2006). A set of recombineering plasmids for gram-negative bacteria. Gene 379, 109-115. doi: 10.1016/j.gene.2006.04.018
Desai, S. N., and Clemens, J. D. (2012). An overview of cholera vaccines and their public health implications. Curr. Opin. Pediatr. 24, 85-91. doi: 10.1097/MOP.0b013e32834eb625

Douard, G., Praud, K., Cloeckaert, A., and Doublet, B. (2010). The Salmonella genomic island 1 is specifically mobilized in trans by the IncA/C multidrug resistance plasmid family. PLoS ONE 5:e15302. doi: 10.1371/journal.pone.0015302

Doublet, B., Boyd, D., Mulvey, M. R., and Cloeckaert, A. (2005). The Salmonella genomic island 1 is an integrative mobilizable element. Mol. Microbiol. 55, 1911-1924. doi: 10.1111/j.1365-2958.2005.04520.x

Dower, W. J., Miller, J. F., and Ragsdale, C. W. (1988). High efficiency transformation of E. coli by high voltage electroporation. Nucleic Acids Res. 16, 6127-6145. doi: 10.1093/nar/16.13.6127

Doyle, M., Fookes, M., Ivens, A., Mangan, M. W., Wain, J., and Dorman, C. J. (2007). An H-NS-like stealth protein aids horizontal DNA transmission in bacteria. Science 315, 251-252. doi: 10.1126/science.1137550

Fernandez-Alarcon, C., Singer, R. S., and Johnson, T. J. (2011). Comparative genomics of multidrug resistance-encoding IncA/C plasmids from commensal and pathogenic Escherichia coli from multiple animal sources. PLoS ONE 6:e23415. doi: 10.1371/journal.pone.0023415

Fricke, W. F., Welch, T. J., Mcdermott, P. F., Mammel, M. K., Leclerc, J. E., White, D. G., et al. (2009). Comparative genomics of the IncA/C multidrug resistance plasmid family. J. Bacteriol. 191, 4750-4757. doi: 10.1128/JB.00189-09

Garrigue, G. P., Ndayo, M., Sicard, J. M., Fonkoua, M. C., Lemao, G., Durand, J. P., et al. (1986). [Antibiotic resistance of strains of Vibrio cholerae eltor isolated in Douala (Cameroon)]. Bull. Soc. Pathol. Exot. Filiales 79, 305-312.

Garriss, G., and Burrus, V. (2013). "Integrating conjugative elements of the SXT/R391 family," in Bacterial Integrative Mobile Genetic Elements, eds A. P. Roberts and P. Mullany (Austin, TX: Landes Biosciences), 217-234.

Garriss, G., Poulin-Laprade, D., and Burrus, V. (2013). DNA-damaging agents induce the RecA-independent homologous recombination functions of integrating conjugative elements of the SXT/R391 family. J. Bacteriol. 195, 1991-2003. doi: 10.1128/JB.02090-12

Garriss, G., Waldor, M. K., and Burrus, V. (2009). Mobile antibiotic resistance encoding elements promote their own diversity. PLoS Genet. 5:e1000775. doi: 10.1371/journal.pgen.1000775

Giske, C. G., Froding, I., Hasan, C. M., Turlej-Rogacka, A., Toleman, M., Livermore, D., et al. (2012). Diverse sequence types of Klebsiella pneumoniae contribute to the dissemination of $b l a_{N D M-1}$ in India, Sweden, and the United Kingdom. Antimicrob. Agents Chemother. 56, 2735-2738. doi: 10.1128/AAC.06142-11

Glenn, L. M., Lindsey, R. L., Folster, J. P., Pecic, G., Boerlin, P., Gilmour, M. W., et al. (2013). Antimicrobial resistance genes in multidrug-resistant Salmonella enterica isolated from animals, retail meats, and humans in the United States and Canada. Microb. Drug Resist. 19, 175-184. doi: 10.1089/mdr.2012.0177

Goldberg, I., and Mekalanos, J. J. (1986). Effect of a recA mutation on cholera toxin gene amplification and deletion events. J. Bacteriol. 165, 723-731.

Guerin, E., Cambray, G., Sanchez-Alberola, N., Campoy, S., Erill, I., Da Re, S., et al. (2009). The SOS response controls integron recombination. Science 324, 1034. doi: 10.1126/science.1172914

Haldimann, A., and Wanner, B. L. (2001). Conditional-replication, integration, excision, and retrieval plasmid-host systems for gene structure-function studies of bacteria. J. Bacteriol. 183, 6384-6393. doi: 10.1128/JB.183.21.6384-6393.2001

Harris, J. B., Larocque, R. C., Qadri, F., Ryan, E. T., and Calderwood, S. B. (2012) Cholera. Lancet 379, 2466-2476. doi: 10.1016/S0140-6736(12)60436-X

Heidelberg, J. F., Eisen, J. A., Nelson, W. C., Clayton, R. A., Gwinn, M. L., Dodson, R. J., et al. (2000). DNA sequence of both chromosomes of the cholera pathogen Vibrio cholerae. Nature 406, 477-483. doi: 10.1038/35020000

Hochhut, B., Lotfi, Y., Mazel, D., Faruque, S. M., Woodgate, R., and Waldor, M. K. (2001). Molecular analysis of antibiotic resistance gene clusters in vibrio cholerae O139 and O1 SXT constins. Antimicrob. Agents Chemother. 45, 2991-3000. doi: 10.1128/AAC.45.11.2991-3000.2001

Jorgensen, J. H., and Ferraro, M. J. (2009). Antimicrobial susceptibility testing: a review of general principles and contemporary practices. Clin. Infect. Dis. 49, 1749-1755. doi: 10.1086/647952

Katz, L. S., Petkau, A., Beaulaurier, J., Tyler, S., Antonova, E. S., Turnsek, M. A., et al. (2013). Evolutionary dynamics of Vibrio cholerae O1 following a single-source introduction to Haiti. MBio 4:e00398-13. doi: 10.1128/mBio.00398-13

Kruse, H., Sorum, H., Tenover, F. C., and Olsvik, O. (1995). A transferable multiple drug resistance plasmid from Vibrio cholerae O1. Microb. Drug Resist. 1, 203-210. doi: 10.1089/mdr.1995.1.203 
Lang, K. S., Danzeisen, J. L., Xu, W., and Johnson, T. J. (2012). Transcriptome map-

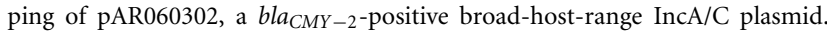
Appl. Environ. Microbiol. 78, 3379-3386. doi: 10.1128/AEM.07199-11

Lawrence, J. G., and Roth, J. R. (1996). Selfish operons: horizontal transfer may drive the evolution of gene clusters. Genetics 143, 1843-1860.

Mazel, D. (2006). Integrons: agents of bacterial evolution. Nat. Rev. Microbiol. 4, 608-620. doi: 10.1038/nrmicro1462

Mazel, D., Dychinco, B., Webb, V. A., and Davies, J. (1998). A distinctive class of integron in the Vibrio cholerae genome. Science 280, 605-608. doi: 10.1126/science.280.5363.605

Mutreja, A., Kim, D. W., Thomson, N. R., Connor, T. R., Lee, J. H., Kariuki, S., et al. (2011). Evidence for several waves of global transmission in the seventh cholera pandemic. Nature 477, 462-465. doi: 10.1038/nature10392

O'shea, Y. A., Finnan, S., Reen, F. J., Morrissey, J. P., O'gara, F., and Boyd, E. F. (2004a). The Vibrio seventh pandemic island-II is a $26.9 \mathrm{~kb}$ genomic island present in Vibrio cholerae El Tor and O139 serogroup isolates that shows homology to a $43.4 \mathrm{~kb}$ genomic island in V. vulnificus. Microbiology 150, 4053-4063. doi: 10.1099/mic.0.27172-0

O'shea, Y. A., Reen, F. J., Quirke, A. M., and Boyd, E. F. (2004b). Evolutionary genetic analysis of the emergence of epidemic Vibrio cholerae isolates on the basis of comparative nucleotide sequence analysis and multilocus virulence gene profiles. J. Clin. Microbiol. 42, 4657-4671. doi: 10.1128/JCM.42.10.46574671.2004

Osorio, C. R., Marrero, J., Wozniak, R. A., Lemos, M. L., Burrus, V., and Waldor, M. K. (2008). Genomic and functional analysis of ICEPdaSpal, a fish-pathogenderived SXT-related integrating conjugative element that can mobilize a virulence plasmid. J. Bacteriol. 190, 3353-3361. doi: 10.1128/JB.00109-08

Pan, J. C., Ye, R., Wang, H. Q., Xiang, H. Q., Zhang, W., Yu, X. F., et al. (2008). Vibrio cholerae $\mathrm{O} 139$ multiple-drug resistance mediated by Yersinia pestis pIP1202like conjugative plasmids. Antimicrob. Agents. Chemother. 52, 3829-3836. doi: 10.1128/AAC.00375-08

Pariseau, É., Massé, D. I., Masse, L., Topp, E., Burrus, V., and Malouin, F. (2013). Coagulation-flocculation pre-treatment of surface water used on dairy farms and evaluation of bacterial viability and gene transfer in treatment sludge. Water Qual. Res. J. Can. 48, 111-120. doi: 10.2166/wqric.2013.140

Petkau, A., Stuart-Edwards, M., Stothard, P., and Van Domselaar, G. (2010). Interactive microbial genome visualization with GView. Bioinformatics 26, 3125-3126. doi: 10.1093/bioinformatics/btq588

Pugliese, N., Maimone, F., Scrascia, M., Materu, S. F., and Pazzani, C. (2009). SXTrelated integrating conjugative element and IncC plasmids in Vibrio cholerae O1 strains in Eastern Africa. J. Antimicrob. Chemother. 63, 438-442. doi: 10.1093/jac/dkn542

Reimer, A. R., Van Domselaar, G., Stroika, S., Walker, M., Kent, H., Tarr, C., et al. (2011). Comparative genomics of Vibrio cholerae from Haiti, Asia, and Africa. Emerg. Infect. Dis. 17, 2113-2121. doi: 10.3201/eid1711.110794

Rodrigue, S., Materna, A. C., Timberlake, S. C., Blackburn, M. C., Malmstrom, R. R., Alm, E. J., et al. (2010). Unlocking short read sequencing for metagenomics. PLoS ONE 5:e11840. doi: 10.1371/journal.pone.0011840

Sievers, F., Wilm, A., Dineen, D., Gibson, T. J., Karplus, K., Li, W., et al. (2011). Fast, scalable generation of high-quality protein multiple sequence alignments using Clustal Omega. Mol. Syst. Biol. 7, 539. doi: 10.1038/msb.2011.75

Singer, M., Baker, T. A., Schnitzler, G., Deischel, S. M., Goel, M., Dove, W., et al. (1989). A collection of strains containing genetically linked alternating antibiotic resistance elements for genetic mapping of Escherichia coli. Microbiol. Rev. $53,1-24$.
Sjolund-Karlsson, M., Reimer, A., Folster, J. P., Walker, M., Dahourou, G. A., Batra, D. G., et al. (2011). Drug-resistance mechanisms in Vibrio cholerae O1 outbreak strain, Haiti, 2010. Emerg. Infect. Dis. 17, 2151-2154. doi: 10.3201/eid1711.110720

Stalder, T., Barraud, O., Casellas, M., Dagot, C., and Ploy, M. C. (2012). Integron involvement in environmental spread of antibiotic resistance. Front. Microbiol. 3:119. doi: 10.3389/fmicb.2012.00119

Sundaram, S., and Murthy, K. V. (1984). Transferable plasmid-mediated drug resistance among non-O1 Vibrio cholerae and rough strains of Vibrio cholerae from Tamilnadu, India. J. Hyg. (Lond.) 92, 59-65. doi: 10.1017/S0022172400064032

Thungapathra, M., Amita, Sinha, K. K., Chaudhuri, S. R., Garg, P., Ramamurthy, T., et al. (2002). Occurrence of antibiotic resistance gene cassettes aac(6')-Ib, dfrA5, dfrA12, and ereA2 in class I integrons in non-O1, non-O139 Vibrio cholerae strains in India. Antimicrob. Agents Chemother. 46, 2948-2955. doi: 10.1128/ AAC.46.9.2948-2955.2002

Toussaint, A., and Merlin, C. (2002). Mobile elements as a combination of functional modules. Plasmid 47, 26-35. doi: 10.1006/plas.2001.1552

Waldor, M. K., and Mekalanos, J. J. (1996). Lysogenic conversion by a filamentous phage encoding cholera toxin. Science 272, 1910-1914. doi: 10.1126/science. 272.5270 .1910

Waldor, M. K., Tschape, H., and Mekalanos, J. J. (1996). A new type of conjugative transposon encodes resistance to sulfamethoxazole, trimethoprim, and streptomycin in Vibrio cholerae O139. J. Bacteriol. 178, 4157-4165.

Welch, T. J., Fricke, W. F., Mcdermott, P. F., White, D. G., Rosso, M. L., Rasko, D. A., et al. (2007). Multiple antimicrobial resistance in plague: an emerging public health risk. PLoS ONE 2:e309. doi: 10.1371/journal.pone.0000309

Wozniak, R. A., Fouts, D. E., Spagnoletti, M., Colombo, M. M., Ceccarelli, D., Garriss, G., et al. (2009). Comparative ICE genomics: insights into the evolution of the SXT/R391 family of ICEs. PLoS Genet. 5:e1000786. doi: 10.1371/journal.pgen.1000786

Yu, L., Zhou, Y., Wang, R., Lou, J., Zhang, L., Li, J., et al. (2012). Multiple antibiotic resistance of Vibrio cholerae serogroup O139 in China from 1993 to 2009. PLoS ONE 7:e38633. doi: 10.1371/journal.pone.0038633

Zhang, D., Iyer, L. M., and Aravind, L. (2011). A novel immunity system for bacterial nucleic acid degrading toxins and its recruitment in various eukaryotic and DNA viral systems. Nucleic Acids Res. 39, 4532-4552. doi: 10.1093/nar/gkr036

Conflict of Interest Statement: The authors declare that the research was conducted in the absence of any commercial or financial relationships that could be construed as a potential conflict of interest.

Received: 26 August 2013; paper pending published: 06 October 2013; accepted: 21 January 2014; published online: 06 February 2014.

Citation: Carraro N, Sauvé M, Matteau D, Lauzon G, Rodrigue S and Burrus V (2014) Development of pVCR94 $\triangle X$ from Vibrio cholerae, a prototype for studying multidrug resistant IncA/C conjugative plasmids. Front. Microbiol. 5:44. doi: 10.3389/ fmicb.2014.00044

This article was submitted to Aquatic Microbiology, a section of the journal Frontiers in Microbiology.

Copyright (c) 2014 Carraro, Sauvé, Matteau, Lauzon, Rodrigue and Burrus. This is an open-access article distributed under the terms of the Creative Commons Attribution License (CC BY). The use, distribution or reproduction in other forums is permitted, provided the original author(s) or licensor are credited and that the original publication in this journal is cited, in accordance with accepted academic practice. No use, distribution or reproduction is permitted which does not comply with these terms. 